\title{
Superior Wall of the Nasopharynx
}

National Cancer Institute

\section{Source}

National Cancer Institute. Superior Wall of the Nasopharynx. NCI Thesaurus. Code

C12242.

The roof of the nasopharynx. 